\title{
Alimentar e Nutrir: Sentidos e Significados em Cuidados Paliativos Oncológicos
}

To Feed and to Nourish: Significances and Meanings in Oncologic Palliative Care Alimentos y Nutrición: Sentidos y Significados en los Cuidados Paliativos Oncológicos

\author{
Mariana Fernandes Costa'; Jorge Coelho Soares ${ }^{2}$
}

\section{Resumo}

Introduçáo: A formação acadêmica do nutricionista não tem tratado devidamente o tema "alimentação" como fenômeno psicobiossociocultural, fato preocupante na medida em que os elementos de trabalho desse profissional sáo o homem e a sua comida. Objetivo: Compreender os sentidos e significados da alimentação e nutrição nos cuidados paliativos oncológicos para pacientes e cuidadores analisados no Brasil e em Portugal. Método: Pesquisa qualitativa, de caráter exploratório-descritivo, realizado com pacientes e cuidadores em instituiçóes de saúde do Brasil e Portugal, no ano de 2013, cujos dados foram produzidos por entrevistas semiabertas, utilizando-se a análise do discurso do sujeito coletivo para compreender os sentidos e significados da alimentação e nutrição para os entrevistados. Resultados: Participaram 14 pacientes oncológicos adultos e 14 cuidadores. A ideia central mais frequente foi: se não comer, não pode viver, presente no discurso de $100 \%$ dos pacientes e $78 \%$ dos cuidadores analisados. Os discursos dos brasileiros e portugueses se complementam, existindo mais semelhanças do que diferenças no aspecto alimentação e nutrição nos cuidados paliativos oncológicos entre Brasil e Portugal. Conclusão: O sentido primordial da alimentação e nutrição está na sua relação condicional para a vida, demonstrando ser fundamental o seu valor cultural e social, cheio de significado simbólico e grande carga emocional.

Palavras-chave: Cuidados Paliativos; Neoplasias; Alimentação; Nutrição em Saúde Pública; Cuidadores.

\footnotetext{
${ }^{1}$ Nutricionista Clínica do Serviço de Nutrição do Hospital do Câncer IV do Instituto Nacional de Câncer José Alencar Gomes da Silva. Ministério da Saúde. (HC IV/INCA/MS). Doutora em Alimentação, Nutrição e Saúde e Doutora em Psicologia Social da Universidade do Estado do Rio de Janeiro (UERJ). Rio de Janeiro (RJ), Brasil. E-mail: marifcosta@gmail.com

${ }^{2}$ Doutor em Comunicaçáo Social pela Universidade Federal do Rio de Janeiro (UFRJ). Professor do Programa de Pós-Graduaçáo em Psicologia Social do Instituto de Psicologia da UERJ. Rio de Janeiro (RJ), Brasil. E-mail: jorge.coelho.soares@gmail.com

Endereço para correspondência: Mariana Fernandes Costa. Rua Domingues de Sá, 381 - apartamento 704 - Icaraí. Niterói (RJ), Brasil. CEP: $24220-090$.

E-mail: marifcosta@gmail.com
} 


\section{INTRODUÇÃO}

Os cursos de nutrição, compreendidos na lógica fragmentada dos saberes em saúde, em sua maioria conjecturada dentro do modelo biomédico, têm dado pouca ou nenhuma importância às dimensóes humana e social dos sujeitos na trajetória de formação acadêmico-profissional do nutricionista, bem como não têm tratado devidamente o tema "alimentaçáo" como fenômeno psicobiossociocultural. Isso passa a ser preocupante na medida em que os elementos de trabalho desse profissional são o homem e a sua comida: um processo relacional demasiadamente complexo ${ }^{1}$ que envolve vários aspectos simbólicos com muitos sentidos e significados.

De acordo com a Organizaçáo Mundial da Saúde $(\mathrm{OMS})^{2}$, cuidados paliativos é uma abordagem que melhora a qualidade de vida dos pacientes e seus familiares frente a problemas associados à doença terminal por meio de prevenção e alívio do sofrimento, identificando, avaliando e tratando a dor e outros problemas físicos, psicossociais e espirituais. Segundo Cícely Saunders ${ }^{3}$, o objetivo do cuidado paliativo é a melhor qualidade de vida possível para os pacientes e suas famílias. Sendo assim, antes da morte, ainda temos vida, apesar de próxima do fim, deve-se garantir o atendimento do ser humano em sua totalidade, promovendo o bem-estar global e mantendo sua dignidade, de modo que possa viver a sua morte e não seja expropriado de sua vida. Os cuidados ao fim de vida referem-se, em geral, aos últimos dias ou últimas 72 horas de vida. O reconhecimento dessa fase pode ser difícil, mas é extremamente necessário para o planejamento do cuidado e preparo do paciente e sua família para perdas e óbito.

Este trabalho justifica-se pela escassez de estudos na literatura científica sobre alimentação e nutrição em cuidados paliativos, principalmente em unidades hospitalares do serviço público, conforme a revisão bibliográfica realizada previamente à elaboraçáo do projeto de pesquisa. Outros fatores que também motivaram a realização do estudo é a sua relevância para a sociedade pelos benefícios à clientela atendida e aos profissionais, atuantes na área de cuidados paliativos, pois possibilitará compreender os sentidos e significados atribuídos à alimentação e nutrição, de modo a oferecer conforto e apoio aos pacientes internados e aos seus cuidadores, além de desenvolver estratégias que diminuam as barreiras comunicacionais e aliviem o sofrimento daqueles envolvidos contribuindo para o aprimoramento das atitudes perante a morte. Viver o pouco tempo que se dispóe com qualidade é sem dúvida o objetivo último de quem cuida e é cuidado.

Por razóes históricas e de fenômenos recentes de imigração, Brasil e Portugal compartilham de uma influência cultural, costumes similares e uma mesma língua. Desse modo, o objetivo do estudo foi compreender os sentidos e significados da alimentação e nutrição nos cuidados paliativos oncológicos para pacientes e cuidadores, entrevistados durante internaçáo hospitalar, no Brasil e em Portugal. A escolha por entrevistar pacientes e cuidadores justifica-se pelo envolvimento desses sujeitos em todas as etapas do processo da doença, participando ativamente nas tomadas de decisóes. A equipe multiprofissional de cuidados paliativos enfrenta situaçốes nas quais a decisão de fornecer ou não alimentação requer, além da avaliação clínica dos pacientes, abertura para comunicação sobre as expectativas dos pacientes e também de seus cuidadores, tendo as instituições nos dois países semelhante estrutura e concepção sobre os cuidados paliativos.

$\mathrm{Na}$ prática clínica, por exemplo, observa-se que, quando a situação do paciente em cuidados paliativos já se apresenta muito grave, sem prognóstico de melhora ou de reversão, a diminuição na aceitação da alimentação e até mesmo a recusa alimentar são frequentes, causando muita angústia aos familiares, por isso os profissionais envolvidos no tratamento precisam estar aptos a identificar os reais benefícios da alimentação, no que se refere à qualidade de vida do paciente, analisando também as questôes trazidas pelos cuidadores. Desse modo, o fato de entrevistar ambos contemplou maior riqueza de conteúdo ao trabalho sobre os sentidos e significados da alimentação e nutrição.

\section{MÉTODO}

Trata-se de uma pesquisa qualitativa, exploratório-descritiva, de perspectiva interpretativa. Foram realizadas entrevistas semiabertas, audiogravadas, guiadas por três perguntas sobre as mudanças na alimentação com o processo da doença, a adaptação e as estratégias utilizadas, e os sentidos e significados da alimentação e nutrição para pacientes e cuidadores nos cuidados paliativos, sendo interesse deste trabalho apresentar somente a ideia central mais frequente sobre o último tópico. Após transcrição das entrevistas, utilizou-se a técnica da análise de discurso do sujeito coletivo (DSC) $)^{4}$. Alguns dados clínicos e sociodemográficos foram colhidos em prontuários (sexo, idade, diagnóstico, tipos de tratamentos realizados, progressão de doença, metástases, sinais e sintomas, Karnofsky Performance Status (KPS) e via alimentar) e com os entrevistados (sexo, idade, profissão e vínculo com o paciente).

O projeto foi previamente aprovado pelos Comitês de Ética e Pesquisa da Universidade do Estado do Rio de Janeiro (UERJ) (453.837), do Instituto Nacional de Câncer José Alencar Gomes da Silva (INCA) (462.858) e do Instituto Português de Oncologia Francisco Gentil 
(IPO) Porto, Portugal (108/2013). Todos convidados aceitaram participar voluntariamente do estudo e assinaram o Termo de Consentimento Livre e Esclarecido (TCLE).

Delinearam-se como participantes do estudo o paciente oncológico adulto, em cuidados paliativos, internado em unidades hospitalares especializadas, e cuidadores que estivessem acompanhando os pacientes. Como critérios de inclusão, foram considerados os pacientes que mantinham o nível de consciência e a fala preservados, e excluídos os cuidadores que tinham alteraçóes cognitivas, de modo que fossem capazes de prover os dados necessários à questáo principal da pesquisa. A amostragem foi feita por conveniência, independente do tempo de internação hospitalar, sendo as entrevistas realizadas ao longo do primeiro semestre de 2013, no Hospital do Câncer IV do INCA, Rio de Janeiro (RJ), Brasil, e no Serviço de Cuidados Paliativos do IPO, Porto, Portugal. Todos os convidados aceitaram participar.

Os depoimentos dos pacientes e cuidadores entrevistados foram organizados em forma de DSC que tem como objetivo elencar e articular uma série de operaçóes sobre a matéria-prima de depoimentos coletados em pesquisas empíricas por meio de questóes abertas, a fim de obter o pensamento coletivo. O painel de discursos de sujeitos coletivos resultante dessas operaçóes é composto de extratos de diferentes depoimentos individuais, sendo redigido na primeira pessoa do singular, com vistas a produzir no receptor o efeito de uma opiniáo coletiva ${ }^{5}$.

Para confecção dos DSC, foram criadas algumas figuras metodológicas: expressōes-chave, ideias centrais, ancoragem e DSC. As expressôes-chave correspondem a pedaços, trechos ou transcriçóes literais do discurso, que devem ser destacadas pelo pesquisador e que revelam a essência do depoimento; em geral, correspondem às questōes da pesquisa. São uma espécie de prova discursivo-empírica da verdade das ideias centrais e das ancoragens e vice-versa. É com a matéria-prima das expressões-chave que se constroem os DSC. As ideias centrais correspondem a um nome ou expressão linguística que revela e descreve, da maneira mais sintética, precisa e fidedigna possível, o sentido de cada um dos discursos analisados e de cada conjunto homogêneo de expressóes-chave, que posteriormente originará o DSC. Podem ser resgatadas por meio de descriçóes diretas do sentido do depoimento, revelando o que foi dito ou através de descrições indiretas ou mediatas, que revelam o tema do depoimento ou sobre o que o sujeito enunciador está falando. A ancoragem é a manifestação linguística de uma dada teoria, ou ideologia, ou crença que o autor do discurso professa. Quase todo o discurso tem uma ancoragem na medida em que está quase sempre alicerçado em pressupostos, teorias, conceitos e hipóteses.
O DSC é um discurso-síntese composto pelas expressốes-chave que têm a mesma ideia central ou ancoragem, o qual passa a representar a fala do social ou o pensamento coletivo redigido na primeira pessoa do singular. É a principal figura metodológica. Para a elaboração do DSC, os discursos em estado bruto são submetidos inicialmente a um trabalho analítico de decomposição, que consiste em selecionar as principais ancoragens e/ou ideias centrais presentes em cada um dos discursos individuais e em todos eles reunidos, terminando sob uma forma sintética, em que se busca a reconstituição discursiva da representação social. A proposta do DSC consiste em analisar o material verbal coletado extraindose dos depoimentos as suas correspondentes expressôes-chave. Com as expressóes-chave das ideias centrais ou ancoragens semelhantes, compóe-se um ou vários discursos. Para organizar os depoimentos dos pacientes e cuidadores entrevistados, utilizou-se a tabulação de dados que inclui Instrumentos de Análise do Discurso (IAD) na qual as expressôes-chave de mesma ideia central foram reunidas para formação do DSC. ${ }^{4}$ Os dados foram coletados e analisados por único pesquisador.

\section{RESULTADOS}

Participaram do estudo sete pacientes adultos e sete cuidadores em cada hospital, totalizando 28 pessoas. Entre os pacientes entrevistados no INCA, quatro eram do sexo masculino e três, feminino. A média de idade foi 65,86 $\pm 8,11$ anos. Em relação à região acometida, três tinham câncer na região abdominal, dois no tórax, um de origem ginecológica e um na regiáo de cabeça e pescoço. Os dados de tratamentos anteriores mostram que cinco fizeram radioterapia, dois, quimioterapia e nenhum dos casos teve indicação cirúrgica. Além disso, dois pacientes eram virgens de tratamento. Todos tinham progressão de doença local e três apresentavam metástase. Quanto aos sinais e sintomas, quatro tinham queixa do trato gastrointestinal, dois com dor, um apresentando dispneia e um com fadiga. O KPS dos pacientes variou de $30 \%$ a $60 \%$. Todos os pacientes entrevistados no INCA estavam com nível de consciência alerta e se alimentavam pela boca, apenas um também tinha gastrostomia como via alternativa.

Os cuidadores do INCA que participaram das entrevistas tinham idade de 53,29 $\pm 7,70$ anos, sendo a maioria do sexo feminino (6). Uma cuidadora apenas tinha vínculo formal (com remuneração financeira), outra era amiga e os demais com parentesco familiar (3 irmãos, 1 mãe e 1 nora). Entre as cuidadoras, três eram empregadas domésticas, as outras tinham profissóes diversas (costureira, assistente administrativo, técnica de enfermagem e professora de ensino superior). 
Em relação aos pacientes entrevistados no IPO Porto, cinco eram do sexo masculino e dois feminino. A média de idade foi 67,86 $\pm 11,19$ anos. Quanto à região acometida, três tinham câncer na região abdominal, dois de origem ginecológica/urológica, um no tórax e um caso de mieloma múltiplo. Quanto ao tratamento, seis fizeram quimioterapia, quatro radioterapia e três submetidos à cirurgia. Apenas um paciente não tinha progressáo de doença. Em relação aos sinais e sintomas, seis tinham queixas do trato gastrointestinal, quatro estavam com dor, dois apresentando dispneia e dois com fadiga. O KPS dos pacientes variou de $30 \%$ a $70 \%$. Todos os pacientes entrevistados no IPO estavam alertas e se alimentando pela boca.

Os cuidadores do IPO Porto que participaram das entrevistas tinham idade de $51,57 \pm 15,77$ anos, sendo cinco mulheres e dois homens. Todos cuidadores apresentavam parentesco familiar (três cônjuges, duas filhas, uma mãe e um irmão). Quanto à ocupação, duas cuidadoras eram do lar, uma estava desempregada e os demais com profissóes diversificadas (bancário, copeira, florista e fabricante de cordas).
Em relação à pergunta - quais os sentidos e significados da alimentaçâo e nutrição? - a ideia central mais frequente foi se não comer, não pode viver, estando presente no discurso de todos os pacientes (100\%) e de 11 cuidadores analisados (78\%). Outras ideias centrais apresentadas para essa pergunta foram: alimentação faz bem, dá força e preserva a autonomia; gosta de comer; alimentação dá prazer e satisfaz a fome; alimentação regrada previne e combate doenças, melhora a saúde e a qualidade de vida; alimentação depende da condição financeira; alimentação é importante socialmente; alimentação para o bom funcionamento do corpo; alimentação depende do estado psicológico; e alimentaçáo com sentido de lembrança, perda e culpa.

Cada DSC recebeu uma identificação para discriminar quando se trata de paciente brasileiro $(\mathrm{PB})$, paciente português $(\mathrm{PP})$, cuidador brasileiro $(\mathrm{CB})$ e cuidador português $(\mathrm{CP})$. Para dar uniformidade ao texto dos discursos, optou-se por considerar os sujeitos como do sexo masculino. Nos Quadros $1 \mathrm{a}$ 4, são apresentadas as expressóes-chave que têm como mesma ideia central se não comer, não pode viver, a partir das quais formaram-se os DSC.

Quadro 1. Expressões-chave e DSC dos pacientes brasileiros - ideia central: se não comer, não pode viver

\begin{tabular}{|c|c|}
\hline Expressões-chave & DSC \\
\hline $\begin{array}{l}\text { 1. A alimentação é tudo. Tudo de bom. A gente não vive } \\
\text { sem comer não. Saco vazio... (risos). A alimentação é tudo. } \\
\text { Tudo de bom. A gente não vive sem comer não. Saco vazio... } \\
\text { A menina que traz a comida fala assim: "O que botar, você } \\
\text { come". Se eu não me alimentar, a minha resistência cai. Aí, } \\
\text { vai atrapalhar. } \\
\text { 2. A pessoa se não comer não pode viver, não pode resistir. } \\
\text { Eu acho que faz muita, como é que se diz, a alimentação } \\
\text { faz bastante coisa pra gente. Se eu não comer, como eu vou } \\
\text { viver? Representa muita coisa para mim. } \\
\text { 3. A menina que traz a comida fala assim: "O que botar, o Sr. } \\
\text { come". Se eu não me alimentar, a minha resistência cai. Aí, } \\
\text { vai atrapalhar. } \\
\text { 4. Porque sem nada, sem nada, sem nada, a gente não pode } \\
\text { ficar. A alimentação tem muita importância! Muita, muita. A } \\
\text { gente tem que fazer alguma coisa, née! } \\
5 \text {. A alimentação é fundamental. Eu acho que sim. Porque } \\
\text { sem alimentação, se você não se alimenta... Sei lá... Não } \\
\text { sobrevive. } \\
\text { 6. A alimentação representa tudo. Grande parte é } \\
\text { alimentação. A alimentação para o ser humano é tudo, né?! É } \\
\text { a base. } \\
\text { 7. É essencial, né?! Essencial. Para a sobrevivência mesmo. } \\
\text { Nesse processo meu da doença, eu acho que é fundamental. } \\
\text { Qual o sentido? Não sei dizer... A alimentação é para me } \\
\text { manter, entendeu? Aquela ração, ração diária para me } \\
\text { manter. Entendeu? Só isso. Não tenho prazer nenhum. Eu } \\
\text { sei que eu tenho que beber alguma coisa, ingerir alguma } \\
\text { coisa... para me manter viva. É mais para me manter mesmo. } \\
\text { Alimentar à medida do possível. }\end{array}$ & $\begin{array}{l}\text { A alimentação representa tudo. Grande parte } \\
\text { é alimentação. A alimentação para o ser } \\
\text { humano é tudo, né?! É a base. A pessoa se } \\
\text { não comer não pode viver, não pode resistir. } \\
\text { Eu acho que faz muita, como é que se diz, a } \\
\text { alimentação faz bastante coisa pra gente. Se } \\
\text { eu não comer, como eu vou viver? Representa } \\
\text { muita coisa para mim. A alimentação é } \\
\text { fundamental. Porque sem alimentação, se você } \\
\text { não se alimenta... Sei lá... Não sobrevive. É } \\
\text { essencial, né?! Essencial. Para a sobrevivência } \\
\text { mesmo. Nesse processo meu da doença, eu } \\
\text { acho que é fundamental. Qual o sentido? Não } \\
\text { sei dizer... A alimentação é para me manter, } \\
\text { entendeu? Aquela ração, ração diária para } \\
\text { me manter. Entendeu? Só isso. Não tenho } \\
\text { prazer nenhum. Eu sei que eu tenho que beber } \\
\text { alguma coisa, ingerir alguma coisa... para me } \\
\text { manter viva. É mais para me manter mesmo. } \\
\text { Alimentar à medida do possível. Porque sem } \\
\text { nada, sem nada, sem nada, a gente não pode } \\
\text { ficar. A alimentação tem muita importância! } \\
\text { Muita, muita. A gente tem que fazer alguma } \\
\text { coisa, né?! }\end{array}$ \\
\hline
\end{tabular}


Quadro 2. Expressões-chave e DSC dos pacientes portugueses - ideia central: se não comer, não pode viver

\begin{tabular}{|c|c|}
\hline Expressões-chave & DSC \\
\hline $\begin{array}{l}\text { 1.É importante. Eu acho que é importante em todos os } \\
\text { aspectos. } \\
\text { 2. Se ficasse sem comer sentiria muita falta. Tem. Tem } \\
\text { importância sim. } \\
\text { 3. A minha alimentação é muito importante. Mas, } \\
\text { a alimentação... Ah, eu prezo muito a alimentação. } \\
\text { Pudera eu voltar a comer outra vez. Eu vim para aqui, } \\
\text { para conseguir voltar a comer em condições. Porque, } \\
\text { se não comer, eu não ia mais estar cá a tomar mais } \\
\text { gente. A gente costuma-se a dizer: "A sede morre-se, } \\
\text { a fome não se morre". Não é assim! A gente também } \\
\text { morre a fome. Chega a um ponto que o organismo } \\
\text { quer... Então, lhe apetece a comer. Portanto, a } \\
\text { alimentação para mim é muito importante. Eu me } \\
\text { lamento imenso por agora não poder comer, neste } \\
\text { momento não poder. } \\
4 \text {. A alimentação faz parte da vida, não é? O que se } \\
\text { come é o que nos traz de pé. É o mais importante. } \\
\text { O mais importante da vida é a alimentação. Depois, } \\
\text { atrás da alimentação, atrás disso, vem o resto, não } \\
\text { é É isso o que penso. Sim. Se não for a alimentação, } \\
\text { se a gente não come... Leva que a gente sem comer, } \\
\text { morre. Não é nada. Se não come, não bebe, não é } \\
\text { nada. Perdeu. Para mim é importante. } \\
5 \text {. Se a gente não comer, não pode viver. Não tem que } \\
\text { morrer! Tem que a gente ter comida, porque também } \\
\text { se não comer, também morre. Se a gente não comer, } \\
\text { aí morre. Se não comer, também morre. Para mim é } \\
\text { importante se alimentar. } \\
\text { 6. A alimentação para mim é fonte de... tem que se } \\
\text { alimentar... temos que nos alimentar, não é? Vou } \\
\text { comer em razão da vida. } \\
\text { 7. Eu acho que é a coisa principal na vida da pessoa. } \\
\text { Fica assim meio difícil. É muito importante. Porque se } \\
\text { a pessoa não se alimentar bem, não consegue viver. }\end{array}$ & $\begin{array}{l}\text { A minha alimentação é muito importante. É } \\
\text { importante. Eu acho que é importante em todos os } \\
\text { aspectos. Se ficasse sem comer sentiria muita falta. } \\
\text { Tem. Tem importância sim. A alimentação faz parte } \\
\text { da vida, não é? O que se come é o que nos traz } \\
\text { de pé. É o mais importante. O mais importante da } \\
\text { vida é a alimentação. Depois, atrás da alimentação, } \\
\text { atrás disso, vem o resto, não é? É isso o que penso. } \\
\text { Se não for a alimentação, se a gente não come... } \\
\text { Leva, que a gente sem comer, morre. Não é nada. } \\
\text { Se não come, não bebe, não é nada. Perdeu. Para } \\
\text { mim é importante... Se a gente não comer, não } \\
\text { pode viver. Não tem que morrer! Tem que a gente } \\
\text { ter comida, porque também se não comer, também } \\
\text { morre. Se a gente não comer, aí morre. Se não } \\
\text { comer, também morre. Para mim é importante se } \\
\text { alimentar. A alimentação para mim é fonte de... } \\
\text { tem que se alimentar... temos que nos alimentar, } \\
\text { não é? Vou comer em razão da vida. Eu acho que } \\
\text { é a coisa principal na vida da pessoa. Fica assim } \\
\text { meio difícil. É muito importante. Porque se a pessoa } \\
\text { não se alimentar bem, não consegue viver. Mas, a } \\
\text { alimentação... Ah, eu prezo muito a alimentação. } \\
\text { No meu caso, pudera eu voltar a comer outra vez. } \\
\text { Eu vim para aqui, para conseguir voltar a comer em } \\
\text { condições. Porque, se não comer, eu não ia mais estar } \\
\text { cá a tomar mais gente. A gente costuma-se a dizer: "A } \\
\text { sede morre-se, a fome não se morre". Não é assim! } \\
\text { A gente também morre a fome. Chega a um ponto } \\
\text { que o organismo quer... Então, Ihe apetece a comer. } \\
\text { Portanto, a alimentação para mim é muito importante. } \\
\text { Eu me lamento imenso por agora não poder comer, } \\
\text { neste momento não poder. }\end{array}$ \\
\hline
\end{tabular}

\section{DISCUSSÃO}

O DSC é uma técnica de pesquisa qualitativa que visa a apreender o pensamento de uma coletividade compondo textos a partir dos depoimentos de indivíduos. Portanto, está coerente com o objetivo do estudo que é analisar os sentidos e significados da alimentação e nutrição em cuidados paliativos em duas populaçôes de países diferentes. Neste estudo, o número de entrevistados foi estabelecido seguindo como primeiro critério o ponto de saturação ${ }^{6}$, e depois um número equitativo de entrevistados entre os grupos.

Os pacientes e cuidadores selecionados no Brasil e em Portugal para entrevista apresentavam características semelhantes em relação às variáveis sexo, idade, localização do tumor, via alimentar, profissão e vínculo com o paciente, alcançando a homogeneidade intergrupos e a heterogeneidade intragrupos nos dois países para obter maior riqueza e variabilidade dos depoimentos, o que permite inferir que as respostas são válidas para responder aos objetivos do estudo. As variáveis clínicas e sociodemográficas incluídas demonstraram que não havia discrepância entre os grupos analisados de modo que viessem a interferir no discurso coletivo, sendo esse o material primordial de análise neste estudo.

$\mathrm{O}$ alimentar e o nutrir são palavras que circulam na cultura brasileira como sinônimos, com ligeiras variações de aplicação, na maioria das vezes definidas por questóes circunstanciais, ou práticas do senso comum que, quando colocadas sob a lente da ciência, podem ser esclarecedoras da realidade em que habitam, assumindo significados peculiares, construindo sentidos específicos nas ações sociais ${ }^{7}$. Pode-se dizer que o mesmo ocorre na cultura portuguesa, como evidenciado nos discursos.

Segundo a American Dietetic Association ${ }^{8}$, a alimentação para o paciente sob cuidados paliativos deve propiciar prazer, conforto emocional, diminuição da ansiedade e aumento da autoestima, além de permitir 
Quadro 3. Expressões-chave e DSC dos cuidadores brasileiros - ideia central: se não comer, não pode viver

\begin{tabular}{|c|c|}
\hline & DSC \\
\hline $\begin{array}{l}\text { 1. Se eu não comer eu não fico em pé não (risos). Se eu } \\
\text { não comer eu não fico em pé não. } \\
\text { 2. Eu posso falar pra você que a minha irmã tá vivendo! } \\
\text { Minha irmã tá comendo. Minha irmã tá indo no } \\
\text { banheiro. Minha irmã tá falando. Ela está vivendo! Ela } \\
\text { não tá passando uma roupa, ela não tá lavando uma } \\
\text { roupa. Mas ela tá vivendo! Porque ela fala. Ela sabe o } \\
\text { que ela quer da vida. Tá lúcida! } \\
\text { 3. A alimentação é tudo. É muito importante sim. } \\
\text { 4. A recusa dele é por não conseguir comer. Eu vejo que } \\
\text { o meu filho está morrendo. Isso para mim... } \\
5 \text {. Eu acho que a gente precisa da alimentação para } \\
\text { sobreviver, não é isso? Então, isso é o que eu acho, } \\
\text { que eu penso. Porque a gente tá vendo, a gente sabe } \\
\text { que já tá nessa fase, mas a gente... Eu acho que é até } \\
\text { egoísmo, porque a gente não quer perder. A gente } \\
\text { quer fazer o possível: "não, não, não, de repente se ela } \\
\text { começar a comer, se alimentar, ela vai ficar bem, vou } \\
\text { levar ela para casa". }\end{array}$ & $\begin{array}{l}\text { A alimentação é tudo. É muito importante sim. } \\
\text { Eu posso falar pra você que ele tá vivendo! Ele tá } \\
\text { comendo. Ele tá indo no banheiro. Ele tá falando. } \\
\text { Ele está vivendo! Ele não tá passando uma roupa, } \\
\text { ele não tá lavando uma roupa. Mas, ele tá vivendo! } \\
\text { Porque ele fala. Ele sabe o que ele quer da vida. Tá } \\
\text { lúcido! Eu acho que a gente precisa da alimentação } \\
\text { para sobreviver, não é isso? Então, isso é o que eu } \\
\text { acho, que eu penso. Porque a gente tá vendo, a } \\
\text { gente sabe que já tá nessa fase, mas a gente... Eu } \\
\text { acho que é até egoísmo, porque a gente não quer } \\
\text { perder. A gente quer fazer o possível, de repente } \\
\text { se ele começar a comer, se alimentar, ele vai } \\
\text { ficar bem, vou levar ele para casa. A recusa dele } \\
\text { é por não conseguir comer. Eu vejo que ele está } \\
\text { morrendo. Isso para mim... Eu sinto saudade de } \\
\text { vê-lo com fome, com vontade de comer, entendeu?! } \\
\text { Não vou dizer que era para mim assim... Eu via que } \\
\text { ele tava vivo, entendeu?! }\end{array}$ \\
\hline
\end{tabular}

Quadro 4. Expressões-chave e DSC dos cuidadores portugueses - ideia central: se não comer, não pode viver

\begin{tabular}{|c|c|}
\hline Expressões-chave & DSC \\
\hline $\begin{array}{l}\text { 1.Eu acho que a alimentação é um dos pontos } \\
\text { fundamentais na vida de uma pessoa... mais primordiais } \\
\text { que existe na vida. } \\
\text { 2. É essencial, claro. Pelo menos acho que é um bem que } \\
\text { temos que ter. Neste caso, a comida acho que é um bem } \\
\text { essencial. } \\
\text { 3. A alimentação é fundamental para todos nós. E uma } \\
\text { boa alimentação melhor ainda. Acho que em todos os } \\
\text { sentidos. Eu acho que nesta altura é o que está no topo. } \\
\text { Independentemente das outras coisas, da força de viver, da } \\
\text { vontade de viver, do fazer, mas, no topo está a alimentação. É } \\
\text { a meta dele. Está relacionado ao ele viver. Acho que é o básico. } \\
\text { Dentro do possível. O pouco que seja já é bom, pelo menos } \\
\text { para o equilibrar por mais algum tempo, não sei quanto... } \\
4 \text {. Acho que isso é uma das coisas mais importantes. Isso } \\
\text { é uma parte fundamental da nossa vida. Para toda a } \\
\text { gente. Toda a gente. } \\
5 \text {. Enquanto a gente está vivo a pessoa tem de... tem de } \\
\text { comer, não é? Eu penso que ele tem que... a pessoa tem } \\
\text { que se alimentar. Porque então se não vamos o dar o } \\
\text { de comer o que é que vai... o que é que passa? Como é } \\
\text { que vamos fazer? Pelo menos enquanto está aqui, tem } \\
\text { que se alimentar e temos que o tratar o melhor que a } \\
\text { gente puder. A pessoa está viva, não é? Não morreu } \\
\text { ainda. A alimentação... a alimentação acho que é o } \\
\text { tudo, porque se deixamos de alimentar neste momento... } \\
\text { Portanto, se ele não tiver alimentação nenhuma, não lhe } \\
\text { dou muito tempo. Ao menos enquanto está internado, } \\
\text { acho que não lhe falte nada e, ao menos comer. Porque } \\
\text { se não come, morre mesmo. E vai morrer um dia. Mas, } \\
\text { ao menos, tem que... tem que se alimentar. Portanto, a } \\
\text { alimentação é muito importante. Muita importância. Não } \\
\text { só quando uma pessoa está doente. Portanto, é muito } \\
\text { importante. Para a nossa vida. Sei lá... } \\
\text { 6. A alimentação é importante. Tem que se alimentar } \\
\text { para continuar a viver, não é? Sem se alimentar, não se } \\
\text { consegue viver. }\end{array}$ & $\begin{array}{l}\text { A alimentação é uma das coisas mais fundamentais, } \\
\text { mais primordiais que existe na vida. É essencial, } \\
\text { claro. Pelo menos acho que é um bem que temos } \\
\text { que ter. Neste caso, a comida acho que é um } \\
\text { bem essencial. Acho que isso é uma das coisas } \\
\text { mais importantes. Isso é uma parte fundamental } \\
\text { da nossa vida. Para toda a gente. Toda a gente. } \\
\text { A alimentação é fundamental para todos nós. E } \\
\text { uma boa alimentação melhor ainda. Acho que em } \\
\text { todos os sentidos. Eu acho que nesta altura é o } \\
\text { que está no topo. Independentemente das outras } \\
\text { coisas, da força de viver, da vontade de viver, do } \\
\text { fazer, mas, no topo está a alimentação. É a meta } \\
\text { dele. Está relacionado ao ele viver. Acho que é o } \\
\text { básico. Dentro do possível. O pouco que seja já é } \\
\text { bom, pelo menos para o equilibrar por mais algum } \\
\text { tempo, não sei quanto... Enquanto a gente está vivo } \\
\text { a pessoa tem de... tem de comer não é? Eu penso } \\
\text { que ele tem que... a pessoa tem que se alimentar. } \\
\text { Porque então se não vamos o dar o de comer o } \\
\text { que é que vai... o que é que passa? Como é que } \\
\text { vamos fazer? Pelo menos enquanto está aqui, tem } \\
\text { que se alimentar e temos que o tratar o melhor } \\
\text { que a gente puder. A pessoa está viva, não é? Não } \\
\text { morreu ainda. A alimentação... a alimentação } \\
\text { acho que é o tudo, porque se deixamos de } \\
\text { alimentar neste momento... Portanto, se ele não } \\
\text { tiver alimentação nenhuma, não lhe dou muito } \\
\text { tempo. Ao menos enquanto está internado, acho } \\
\text { que não lhe falte nada e, ao menos comer. Porque } \\
\text { se não come, morre mesmo. E vai morrer um dia. } \\
\text { Mas, ao menos, tem que... tem que se alimentar. } \\
\text { Portanto, a alimentação é muito importante. Não só } \\
\text { quando uma pessoa está doente. Portanto, é muito } \\
\text { importante. Para a nossa vida. Sei lá... Tem que se } \\
\text { alimentar para continuar a viver, não é? Sem se } \\
\text { alimentar, não se consegue viver. }\end{array}$ \\
\hline
\end{tabular}


maior integração e comunicação com seus familiares. A alimentação deve, prioritariamente, ser fornecida por via oral, porque é natural, mais fisiológica; logo, mais aceitável, desde que o sistema digestório esteja íntegro e o paciente manifeste o desejo e apresente as condiçóes clínicas necessárias para realizá-la. Entretanto, em diferentes situaçóes, alguns indivíduos não estão aptos a alimentar-se adequadamente de forma espontânea e por via oral, necessitando de outros meios para que continuem recebendo nutrientes. Nesses casos, pode ser adotada a via enteral ou parenteral como complementação ou até mesmo de forma exclusiva.

A equipe multiprofissional de cuidados paliativos enfrenta situaçôes nas quais a decisão de fornecer ou não terapia nutricional requer conhecimento e respeito pelos desejos dos pacientes, além de avaliação das suas expectativas e de seus cuidadores com abertura para comunicação efetiva'. Uma parte crescente de profissionais paliativistas advoga que o desconforto e as complicaçóes oriundas da terapia nutricional superam os benefícios que são controversos, pois não há estudos comprovando o aumento da sobrevida e, em especial, a melhora da qualidade de vida dos pacientes fora das possibilidades de cura $^{10}$. Escolher entre instituir ou não, continuar ou retirar o suporte nutricional, é um dilema ético que deve levar em consideração os princípios da bioética: autonomia, beneficência, não maleficência e justiça. A autonomia tem como ideal que a escolha seja feita pelo próprio paciente. A beneficência refere-se a aliviar o sofrimento do paciente, a não maleficência corresponde a não prejudicar, e a justiça refere-se a fornecer uma boa qualidade de vida restante a esse paciente ${ }^{11,12}$.

Mesmo considerando os conflitos culturais que tais debates produzem, é importante estabelecer um olhar individualizado nos diferentes contextos clínicos, dirigido para atitudes de conforto no processo de morrer e considerar que, em alguns momentos, a nutrição enteral ou a parenteral podem ser danosas à qualidade de vida dos pacientes ${ }^{10}$. Assim, essas situaçóes atingem, em especial, o nutricionista, que é o responsável por oferecer esclarecimentos aos pacientes e cuidadores sobre a dieta ${ }^{13}$.

O nutricionista, dentro de uma Unidade de Cuidados Paliativos, deve conhecer o prognóstico da doença e a expectativa de vida do indivíduo, quais os sintomas apresentados, o grau de reversibilidade da desnutriçáo $\mathrm{e}$, dentro desses aspectos, junto com paciente, familiar e equipe, discutir qual terapia nutricional é mais indicada, avaliando os riscos e benefícios ${ }^{14}$. Então, a inserção do nutricionista na equipe de cuidados paliativos é fundamental, visto que executa um papel muito importante no dia a dia de acompanhamento dos pacientes internados ${ }^{15,16}$.
Segundo Cañizo Fernández-Roldán ${ }^{17}$, dar de comer e beber é uma ação humana significativa de respeito à vida e ao cuidado dos nossos semelhantes. Por ser fonte de vida, a sua privaçáo significa atentar contra a vida. $\mathrm{O}$ seguinte trecho do discurso do CP deixa clara essa ideia de cuidado com a alimentação e sua relação com a vida, uma vez que o indivíduo ainda está vivo, mesmo nos cuidados paliativos, pois sua morte não pode e não deve ser antecipada, mas sim respeitada:

Enquanto a gente está vivo a pessoa tem de... tem de comer, não é? Eu penso que ele tem que... a pessoa tem que se alimentar. Por que entáo se não vamos o dar o de comer o que é que vai... o que é que passa? Como é que vamos fazer? Pelo menos enquanto está aqui, tem que se alimentar e temos que o tratar o melhor que a gente puder. A pessoa está viva, não é? Não morreu ainda. [...] Tem que se alimentar para continuar a viver, não é? Sem se alimentar, não se consegue viver (CP).

A alimentação está associada à vida, à pessoa se "manter viva", pois sem comer "náo sobrevive". Algumas expressôes mostram esse sentido, como, por exemplo: "a pessoa se nấo comer não pode viver, não pode resistir"; "a gente não vive sem comer não"; "se a gente não comer, não pode viver"; "se a gente não comer, aí morre"; "se não comer, morre". Para pacientes e cuidadores, a alimentação representa "tudo de bom"; "grande parte"; "a base"; "fundamental"; "essencial"; "faz parte da vida"; "principal"; "o mais importante da vida"; "primordial"; "bem essencial"; "o topo".

Em alguns casos, os cuidadores insistem para os pacientes se alimentarem, na esperança de melhorar seu estado de saúde, e possivelmente tentar mantê-los por mais tempo em sua companhia ${ }^{13}$. Apesar de reconhecer a gravidade da situação, o CB demonstra a esperança da melhora e o quanto isso pode estar relacionado à alimentação:

Porque a gente tá vendo, a gente sabe que já tá nessa fase, mas a gente... Eu acho que é até egoísmo, porque a gente não quer perder. A gente quer fazer o possível, de repente se ele começar a comer, se alimentar, ele vai ficar bem, vou levar ele para casa (CB).

Náo poder ou não conseguir se alimentar significa a piora da saúde ${ }^{16}$; ou seja, do estado geral do paciente, o que lhe aproxima da morte. $\mathrm{O} \mathrm{CB}$ confirma claramente essa percepção em seu discurso:

A recusa dele é por não conseguir comer. Eu vejo que ele está morrendo. Isso para mim... Eu sinto saudade de vê-lo com fome, com vontade de comer, entendeu?! Não vou dizer que era para mim, assim... Eu via que ele tava vivo, entendeu?! (CB). 
Portanto, a ideia central se não comer, não pode viver esteve presente em todas as entrevistas com os pacientes e quase todos os cuidadores sobre os sentidos e significados da alimentação e nutriçáo nos cuidados paliativos oncológicos no Brasil e em Portugal, logo comer é viver; ou seja, alimentação é vida. Simone de Beauvoir ${ }^{18}$ conta a experiência que teve sobre a alimentação durante a internação hospitalar até o óbito de sua mãe e como essa crença estava presente:

Depois, dava-lhe o almoço: incapaz de mastigar, comia purés, caldos, carne picada, compotas, cremes; forçava-se a esvaziar o prato: 'Tenho de me alimentar'. Entre as refeições, bebericava sumos com uma mistura de vários frutos frescos: 'São vitaminas. Fazem-me bem'. [...] 'Já não precisas de tomar essa poção. - É melhor que a tome'. E engolia o líquido pastoso. Tinha dificuldade em comer: 'Não te forces; chega, para. - Achas?' Examinava o prato, hesitava: 'Dá-me mais um pouco'. No fim, eu tirava-lhe o prato do alcance da vista: 'Esvaziaste-o', dizia-lhe. De tarde, forçava-se a comer um iogurte. Pedia frequentemente sumo de fruta. .[...] Aspirava por meio de uma pipeta as vitaminas benéficas: uma boca ávida aspirava a vida ${ }^{18}$.

Quando a situação do paciente em cuidados paliativos já se apresenta muito grave, sem prognóstico de melhora ou de reversão, a recusa da alimentação é frequente, causando muita angústia aos familiares, por isso os profissionais envolvidos no tratamento precisam estar aptos a identificar os benefícios da alimentação por via oral, enteral e/ou parenteral, no que se refere à qualidade de vida do paciente ${ }^{19}$. Em paciente impossibilitado de se comunicar devido a estado de coma, rebaixamento do nível de consciência ou confusão mental, os profissionais responsáveis devem considerar a opinião da família e definir com ela qual a melhor conduta a ser adotada ${ }^{13}$.

Por não haver evidências científicas para a decisão de alimentar ou não o paciente e por existir influência cultural importante no que tange à alimentação, a decisão de nutrir até a morte o paciente deve ser multiprofissional e ter o consentimento da família se o paciente não tiver condições de decidir. Caso o paciente opte por náo receber nutrição, sua decisão deve ser respeitada pelos profissionais da saúde e por seus familiares, pois acima de qualquer evidência científica está a autonomia do paciente ${ }^{10}$. Essa decisão não é somente técnica, tendo um forte componente moral envolvido, pois a alimentação e a hidratação têm um significativo valor simbólico em nossa sociedade.

Portanto, o nutricionista precisa ouvir o paciente, respeitar seus desejos e suas necessidades no que se refere à alimentação, levando em consideração a sua autonomia.
O mais importante é proporcionar a diminuição do seu sofrimento, alívio dos sintomas e promover uma melhor qualidade de vida evitando-se muitas vezes medidas fúteis ${ }^{20}$.

Este trabalho contribui para a compreensão dos sentidos e significados atribuídos à alimentação e nutrição nos cuidados paliativos, instrumentalizando profissionais de saúde a oferecer conforto e apoio aos pacientes internados e aos seus respectivos cuidadores. Desse modo, as barreiras comunicacionais podem ser ultrapassadas a fim de aliviar o sofrimento, aprimorando as atitudes perante a morte.

\section{CONCLUSÃO}

A alimentação nos cuidados paliativos oncológicos continua influenciada por inúmeras variáveis e está associada à saúde e à qualidade de vida. A ideia central se nâo comer, não pode viver, presente nos discursos dos sujeitos analisados sobre a alimentação e a nutrição, demonstra que o sentido primordial está na sua relação condicional para a vida, ressaltando ser fundamental o seu valor cultural e social, cheia de significado simbólico e grande carga emocional. Apesar da diferenciação entre os termos nutrição e alimentação no campo científico, para o senso comum, essas palavras aparecem como sinônimos, sem distinção significativa pelos entrevistados.

Assim, o profissional dessa área deve ser o principal difusor da aceitação do morrer e da construção de uma boa morte, sendo um grande desafio transformar o espaço hospitalar destinado aos cuidados dos doentes, singularizar $\mathrm{o}$ atendimento e ter a sensibilidade adequada para entrar em contato com o sofrimento do outro.

\section{CONTRIBUIÇÕES}

Mariana Fernandes Costa participou da concepção e planejamento do estudo; obtenção, análise e interpretação dos dados; redação, revisão crítica e aprovação final da versão publicada. Jorge Coelho Soares orientou todas as etapas da pesquisa.

\section{Declaraçáo de Conflito de Interesses: Nada a Declarar.}

\section{REFERÊNCIAS}

1. Demétrio F, Paiva JB, Fróes AAG, Freitas MCS, Santos LAS. A nutrição clínica ampliada e a humanização da relação nutricionista-paciente: contribuiçôes para reflexão. Rev Nutr. 2011;24(5):743-63.

2. World Health Organization. National cancer control programmes: policies and managerial guidelines. 2nd ed. Geneva: WHO; 2002. 
3. Saunders C. Foreword. In: Doyle D, Hanks G, Cherny $\mathrm{N}$, Calman K, editors. Oxford textbook of palliative medicine. 3 ed. New York: Oxford University Press; 2004. p. v-ix.

4. Lefèvre F, Lefèvre AMC. Discurso do sujeito coletivo: um novo enfoque em pesquisa qualitativa. 2. ed. Caxias do Sul: Educs; 2005.

5. Lefèvre F, Lefèvre AMC. O sujeito coletivo que fala. Interface Comun Saúde Educ. 2006;10(20):517-24.

6. Denzin N, Lincoln Y, editors. Handbook of Qualitative Research. 2nd ed. London: Sage Publication; 2000.

7. Carvalho MCVS, Luz MT, Prado SD. Comer, alimentar e nutrir: categorias analíticas instrumentais no campo da pesquisa científica. Ciênc Saúde Coletiva. 2011;16(1):155-63.

8. American Dietetic Association. Position of the American Dietetic Association: issues in feeding the terminally ill adult. J Am Diet Assoc. 1992;92(8):996-1002.

9. Fuhrman MP, Herrmann VM. Bridging the continuum: nutrition support in palliative and hospice care. Nutr Clin Pract. 2006;21(2):134-41.

10. Reiriz AB, Motter C, Buffon VR, Scatola RP, Fay AS, Manzini M. Cuidados paliativos: há benefícios na nutrição do paciente em fase terminal? Rev Soc Bras Clín Méd. 2008;6(4):150-5.
11. Andrews M, Marian M. Ethical framework for the registered dietitian in decisions regarding withholding/ withdrawing medically assisted nutrition and hydration. J Am Diet Assoc. 2006;106(2):206-8.

12. Chernoff R. Tube feeding patients with dementia. Nutr Clin Pract. 2006;21(2):142-6.

13. Marucci MFN, Fernandes EA. Nutrição e alimentação em cuidados paliativos. In: Santos FS, editor. Cuidados paliativos: diretrizes, humanização e alívio de sintomas. São Paulo: Atheneu; 2011. p. 299-305.

14. Academia Nacional de Cuidados Paliativos (BR). Manual de cuidados paliativos ANCP. São Paulo: ANCP; 2009.

15. Marín Caro MM, Laviano A, Pichard C. Nutritional intervention and quality of life in adult oncology patients. Clini Nutr. 2007;26(3):289-301.

16. Benarroz MDO, Faillace GBD, Barbosa, LA. Bioética e nutrição em cuidados paliativos oncológicos em adultos. Cad Saúde Pública. 2009;25(9):1875-82.

17. Fernández-Roldán AC. Nutrición en el paciente terminal: punto de vista ético. Nutr Hop. 2005;20(2):88-92.

18. Beauvoir S. Uma morte suave. Lisboa: Cotovia; 2008.

19. Pessini L, Bertachini L. organizadores. Humanização e cuidados paliativos. São Paulo: Loyola; 2004.

20. Sochacki M, Barbosa, LA, Silva ACSB, Neves M, Fialho LF. A dor de não mais alimentar. Rev BrasNutr Clín. 2008;23(1):78-80. 


\section{Abstract}

Introduction: The college of nutrition has not treated properly the theme of feeding as a psychobiosociocultural phenomenon. This is worrying because the work elements of this professional are man and his food. Objective: The goal was to understand the meanings and significance of food and nutrition in oncologic palliative care for patients and their caregivers in Brazil and Portugal. Method: A qualitative exploratory-descriptive study, carried out with patients and caregivers in health institutions in Brazil and Portugal in the year 2013, the data of which were produced by semi-open interviews, using discourse analysis of the collective subject to understand the meanings and significances of food and nutrition for the interviewees. Results: The participants were 14 oncology patients and 14 caregivers. The most frequent central idea was: cannot live without eating, present in the discourse of $100 \%$ of the patients and $78 \%$ of the caregivers analyzed. The discourse of the Brazilians and Portuguese complement each other, so there are more similarities than differences regarding food and nutrition in oncologic palliative care in Brazil and Portugal. Conclusion: The primary sense of food and nutrition lies in its conditional relationship to life, demonstrating that their cultural and social value is fundamental, full of symbolic meaning and emotional load.

Key words: Palliative Care; Neoplasms; Feeding; Nutrition, Public Health; Caregivers.

\section{Resumen}

Introducción: La formación académica del nutricionista no ha tratado adecuadamente el tema "alimentación" como fenómeno psicobiossociocultural hecho preocupante en medida los elementos de este trabajo profesional son el hombre y su comida. Objetivo: Comprender los sentidos y significados de alimentación y nutrición en los cuidados paliativos oncológicos para pacientes y cuidadores analizados en Brasil y Portugal. Método: Investigación cualitativa, de carácter exploratorio - descriptivo, realizado con pacientes y cuidadores en las instituciones de salud en Brasil y Portugal, en 2013, cuyos datos fueron producidos por entrevistas semiabiertas, mediante el análisis del discurso del sujeto colectivo para comprender los significados de alimentación y nutrición para los encuestados. Resultados: Participaron 14 pacientes oncológicos adultos y 14 cuidadores. La idea central era más común fue si no como, no puedo vivir, presente en el $100 \%$ de los pacientes del habla y el $78 \%$ de los cuidadores analizados. Los discursos de los brasileńos y portuguesa se complementaron, existiendo más semejanzas que diferencias en el aspecto de alimentación y nutrición en los cuidados paliativos del cáncer entre Brasil y Portugal. Conclusión: El principal sentido de la alimentación y nutrición es en su relación condicional para la vida, demostrando que es esencial para su valor cultural y social, lleno de significado simbólico y de carga emocional.

Palabras clave: Cuidados Paliativos; Neoplasias; Alimentación; Nutrición en Salud Pública; Cuidadores. 